\section{Estudo \\ cobebate}

em Crestão

Planejamento
Revista Estudo \& Debate, Lajeado, v. 25, n. 1, 2018. ISSN 1983-036X

DOI: http://dx.doi.org/10.22410/issn.1983-036X.v25ila2018.1367

\title{
ESTUDO FÍSICO-QUÍMICO E MICROBIOLÓGICO DA ÁGUA COM POTENCIAL REÚSO NÁO POTÁVEL EM INDÚSTRIA DE ALIMENTOS
}

\author{
Fernanda Aline Blatt Theves ${ }^{1}$, Keli Hepp ${ }^{2}$, Claudete Rempel ${ }^{3}$, Mônica Jachetti Maciel ${ }^{4}$
}

\begin{abstract}
Resumo: $\mathrm{O}$ presente trabalho foi desenvolvido em uma indústria de alimentos do segmento de candies e teve como objetivo caracterizar as condiçóes físico-químicas e microbiológicas da água de três linhas de produção para avaliar o potencial reúso para fins não potáveis, empregando-a na lavagem de maquinários, pisos, banheiros e na rega de jardins. A metodologia consistiu na medição do volume e vazão de água gerada no processo de limpeza em cada uma das linhas durante o processo produtivo. Foram coletadas amostras dos efluentes gerados durante as limpezas internas das máquinas, analisando a concentração de sólidos solúveis $\left({ }^{\circ} \mathrm{Bx}\right)$, demanda química de oxigênio (DQO) e potencial hidrogeniônico $(\mathrm{pH})$. Seis amostras foram encaminhadas para as seguintes análises microbiológicas: contagem total de bactérias mesófilas aeróbias, bolores e leveduras, Bacillus cereus, Escherichia coli, Salmonella spp. e Staphylococcus coagulase positiva. As três linhas de produção geram uma média de 5.968 litros de água/dia, DQO média de $60.809 \mathrm{mg} \mathrm{L}^{-1}$ e sólidos solúveis médio igual a 5,0 ${ }^{\circ} \mathrm{Bx}$. Não houve crescimento microbiológico para contagem total de bactérias mesófilas aeróbias na primeira análise (00h00), mas $24 \mathrm{~h}$ depois, houve crescimento de 5 logs nas linhas um e três e na linha dois, 4 logs. Para bolores e leveduras, houve contaminação inicial com aumento de 2 logs na linha um, 4 logs na linha dois e $3 \operatorname{logs}$ na linha três, $24 \mathrm{~h}$ após coleta. Conclui-se que essa água é viável para reúso não potável em um período inferior a $24 \mathrm{~h}$ após seu primeiro uso.
\end{abstract}

Palavras-chave: Efluente industrial. Meio ambiente. Resíduos líquidos.

1 Bióloga. Universidade do Vale do Taquari - Univates. Bióloga da Gaiazul Assessoria Ambiental.

2 Bióloga. Universidade do Vale do Taquari - Univates. Bióloga da Empresa Docile Alimentos SA.

3 Bióloga. Universidade do Vale do Taquari - Univates. Docente dos Programas de Pós-Graduação em Ambiente e Desenvolvimento e em Sistemas Ambientais Sustentáveis.

4 Bióloga. Universidade do Vale do Taquari - Univates. Docente do Programa de Pós-Graduação em Sistemas Ambientais Sustentáveis. 


\title{
PHYSICO-CHEMICAL AND MICROBIOLOGICAL STUDY OF POTENTIAL WATER REUSE IN THE FOOD INDUSTRY
}

\begin{abstract}
This study was conducted in a food industry of candies segment and aimed to characterize the physicochemical and microbiological conditions of the three production lines to assess the potential for reuse of water in food production stages, employing it in the washing of machinery, floors, bathrooms and in the watering of gardens. The method consisted in measuring the measurement of the volume and flow of water generated in the cleaning process in each of the lines during the production process. Internal cleaning of the machines samples were collected by analyzing the soluble solids content $\left({ }^{\circ} \mathrm{Bx}\right)$, chemical oxygen demand (COD) and hydrogenic potential $(\mathrm{pH})$. Six samples were sent to the following microbiological analysis: total count of aerobic mesophilic bacteria, molds and yeasts, Bacillus cereus, Escherichia coli, Salmonella spp. and Staphylococcus coagulase positive. The three production lines produce an average of 5,968 liters of water / day, average COD of $60,809 \mathrm{mg} \mathrm{L}^{-1}$ and soluble solids Average $5.0^{\circ} \mathrm{Bx}$. There were no microbiological growth to total count of aerobic mesophilic bacteria in the first analysis $(00 \mathrm{~h} 00)$ but 24 hours later, there was growth of 5 logs on lines one and on line three and two, four logs. For yeasts and molds, there was initial contamination increase of 2 logs on line one, four logs on the line 2 and $3 \operatorname{logs}$ on line three, 24 hours after collection. It was concluded that this water is feasible to reuse in a period less than 24 hours after its first use.
\end{abstract}

Keywords: Industrial effluent. Environment. Liquid waste.

\section{Introdução e Revisão da Literatura}

A água é fundamental para todos os organismos existentes, porém, este recurso natural vem sendo comprometido através de atividades humanas inadequadas. No planeta, $97 \%$ da água é salgada, 2\% está em geleiras e apenas 1\% é de água doce e encontrada em lençóis freáticos, como lagos e rios (MORAES; JORDÃO, 2002).

No Brasil, muitos rios e lagos são receptores de esgotos domésticos e efluentes industriais sem tratamento, comprometendo sua qualidade e acarretando inúmeros problemas ambientais (MORAES; JORDÃO, 2002). Esse descarte ocorre muitas vezes através de redes clandestinas ligadas ao sistema pluvial (CUNHA et al., 2011).

As indústrias consomem uma grande quantidade de água que é utilizada em diversas atividades, como matéria-prima, reagentes, solventes, transmissão de calor, resfriamento, lavagens, energia (TELLES; COSTA, 2007) estando diretamente ligada ao processo industrial e aos custos de produção, mas as indústrias ainda são vistas como potenciais poluidores, devido à extensa variedade de efluentes gerados, que podem conter metais pesados, resíduos químicos e microrganismos patógenos (DANTAS; SALES, 2009). No entanto, os sistemas de tratamento de efluentes e sistemas de reaproveitamento, como coleta da água da chuva e o reúso de água, tornam-se opçóes valiosas para as indústrias minimizando o desperdício e o consumo (CUNHA et al., 2011). Para Araújo, Santos e Souza (2017), atualmente é relevante que se discuta a importância do reúso de efluente tratado em cenários distintos. A adoção de sistema de reúso possibilita a redução de custos em indústrias e empresas de serviço, como no exemplo pesquisado por Subtil et al. (2016), onde na lavagem de caminhóes, o reúso da água possibilitaria uma redução de R \$2.590,75/ mês no custo operacional do lava-rápido estudado.

O reúso é uma possibilidade de reverter o problema da escassez de água (DANTAS; SALES, 2009). O termo "reúso de água" tem uma definição amplamente aceita: "uso de 
efluentes tratados ou não para fins benéficos, tais como irrigação, uso industrial e fins urbanos não potáveis”. É a utilização dos efluentes tratados em estações ou unidades de tratamento ou, ainda, o uso direto de efluentes para substituir a fonte de água normalmente explorada (MIERZWA; HESPANHOL, 2005).

Existem diversas formas de reúso de água que podem ser decorrentes de açóes planejadas ou não, como o reúso indireto náo planejado (o efluente tratado é lançado no ambiente e após algum tempo de detenção, é captado, tratado e distribuído), o reúso indireto planejado (o efluente tratado é despejado de forma planejada em corpos hídricos não poluídos, diluído e utilizado de maneira controlada) e o reúso direto planejado (após o tratamento, o efluente, é encaminhado diretamente ao local de reúso, não sendo descartado no meio ambiente, sendo mais frequente na irrigação e indústria). A reciclagem de água, aquela utilizada antes de sofrer qualquer tratamento ou descarte, geralmente é empregada na indústria para refrigeração, alimentação de caldeiras e água de processamento (TELLES; COSTA, 2007).

O reúso de água na indústria alimentícia encontra restrições devido à preocupação com a existência de microrganismos, no entanto é possível controlar a segurança do alimento através de monitoramento e análises físico-químicas e microbiológicas qualificadas. A água de reúso está inteiramente relacionada com o desenvolvimento econômico-social, preservação da qualidade ambiental, equilíbrio ecológico e preservação dos recursos ambientais (DANTAS; SALES, 2009). As análises físico-químicas são importantes para identificar, quantificar os elementos presentes e associar o efeito de suas propriedades às questôes ambientais (PARRON; MUNIZ; PEREIRA, 2011), juntamente às análises microbiológicas, possibilitando a caracterização do efluente gerado de acordo com o processo industrial.

O Vale do Taquari/RS, região onde foi realizado o estudo, é reconhecido pela produção de alimentos, tanto em nível primário quanto industrial. De acordo com o Banco de Dados Regional da Univates (BDR, 2011), em 2010, a região contava com 332 indústrias de alimentos, número considerável quando se associa a uma população de 348.471 habitantes (IBGE, 2015). A empresa em estudo é uma das quatro indústrias de balas e derivados existentes nessa regiáo e, de acordo com o IBGE (2012) é classificada como de grande porte e, segundo dados da própria empresa, com um portfólio de 170 produtos e uma produçáo de 1.500 toneladas mensais.

Segundo a Política Nacional de Recursos Hídricos, Lei n 9.433, de 1997, nenhuma água de boa qualidade deverá ser utilizada em atividades que tolerem águas de qualidade inferior. $\mathrm{O}$ reúso de água constitui-se da prática de racionalizar e conservar os recursos hídricos, reduzindo a descarga de poluentes em corpos receptores, diminuindo os custos associados à poluição e contribuindo, assim, para a proteção do meio ambiente e da saúde pública (BRASIL, 2005).

$\mathrm{Na}$ empresa em estudo, o consumo de água para limpeza interna dos maquinários, segundo Eckhard (2013), era um dado não existente, contudo, necessário para avaliação da viabilidade de reúso no processo industrial. 
O presente trabalho teve como objetivos: quantificar a água utilizada para limpeza interna dos maquinários; caracterizar as condiçôes físico-químicas e microbiológicas da água de três linhas de produção e avaliar seu potencial para reúso, utilizando-a na lavagem de maquinários, pisos, banheiros e na rega de jardins.

\section{Metodologia}

O presente trabalho foi realizado em uma empresa de alimentos no segmento de candies, localizada no Vale do Taquari, Rio Grande do Sul. A indústria possui seis linhas de produção, sendo o açúcar, o amido e a gelatina três das principais matérias-primas utilizadas nos seus processos.

O estudo foi realizado no período de agosto a outubro de 2015 e deteve-se nas três linhas, identificadas como "Linha 1", "Linha 2" e "Linha 3", que mais consomem água durante o processo produtivo e consequentemente, geram mais efluentes tendo como destino, a estação de tratamento de efluentes (ETE). A cada troca de produto, parada de máquina ou número determinado de bateladas, ocorre a limpeza interna das máquinas, para evitar qualquer mistura de cor ou aroma no produto seguinte.

Para determinar o volume de água gerado em cada uma das linhas, foram utilizados dois tanques para coleta, sendo um com capacidade para quinhentos litros e outro com capacidade para mil litros. Os tanques foram instalados em uma linha de cada vez, funcionando como recipiente de armazenamento. A cada limpeza, a água foi armazenada temporariamente no tanque, homogeneizada com auxílio de um coletor de inox e retirada para análises, sendo o restante do volume da amostra descartado para a ETE. As amostras foram armazenadas em recipiente plástico, fechado, identificado e encaminhadas ao Laboratório de Controle de Qualidade da empresa, para realização das análises, seguindo métodos validados de determinação, a saber: físico-químicas de sólidos solúveis $(\mathrm{o} \mathrm{Bx})$ (BRASIL, 1986), análise de potencial hidrogeniônico $(\mathrm{pH})$, verificação da demanda química de oxigênio (DQO).

Também foram coletadas seis amostras aleatórias durante o período de testes para a realização de ensaios microbiológicos. $\mathrm{Na}$ Linha 1 , foram coletadas as seguintes amostras: A1, A2, A3 e A4, na Linha 2: A5 e na Linha 3: A6. A diferença no número de amostras obtidas em cada linha refere-se à quantidade de produto produzido no período, demandas de trocas de produtos e limpezas necessárias no processo de produção das diferentes linhas.

As mesmas foram coletadas e acondicionadas em recipiente de vidro estéril, hermeticamente fechado, identificadas e mantidas em refrigeração para que não houvesse alteraçôes microbiológicas. Em seguida foram encaminhadas em caixas de isopor contendo gelo ao Laboratório de Microbiologia Didático, da Universidade do Vale do Taquari Univates. Foram analisadas microbiologicamente no dia da coleta (00h00) e após $24 \mathrm{~h}$. Depois da realização da primeira análise, as amostras foram mantidas em temperatura ambiente, para que simulassem as futuras condiçóes de armazenamento. A metodologia utilizada para as análises e a forma de armazenamento foi escolhida de acordo com as necessidades da empresa. 
As amostras foram analisadas em duplicatas e utilizou-se como referência a Instrução Normativa $n^{\circ}$ 62, de 2003, do Ministério da Agricultura, Pecuária e Abastecimento (MAPA) [13], para as análises de bactérias mesófilas aeróbias, bolores e leveduras, Escherichia coli, Salmonella spp. e Staphylococcus coagulase positiva e para Bacillus cereus, fez-se o uso da metodologia descrita pela International Organization for Standardization (ISO 7932) (ISO, 2004).

As diferenças entre o $\mathrm{pH}$ nas três linhas de produção foram avaliadas através do teste não paramétrico Qui-quadrado. Já os resultados das análises de DQO ( $\left.\mathrm{mg} \mathrm{L}^{-1}\right)$ e sólidos solúveis $\left({ }^{\circ} \mathrm{Bx}\right)$, nas três linhas de produção, foram analisados através do teste não-paramétrico de Kruskal-Wallis, com comparação pelo teste de Dunn, sendo consideradas significativas associaçôes com $\mathrm{p} \leq 0,05$. Para a análise estatística utilizou-se o software estatístico BioEstat (5.3).

\section{Resultados e discussóes}

A fim de oportunizar o reúso da água de limpeza dos processos de produção de candies avaliou-se o volume de água utilizada e a carga orgânica remanescente no efluente do processo. Tendo em vista que a quantidade de produto perdido na limpeza e a carga de poluição dos efluentes gerados nesse processo é consideravelmente elevada, todas as amostras foram analisadas quanto ao volume $(\mathrm{L})$, DQO $\left(\mathrm{mg} \mathrm{L}^{-1}\right)$ e sólidos solúveis $(\mathrm{o} \mathrm{Bx})$, sendo os resultados apresentado na Tabela 1 .

Tabela 1. Resultado das médias obtidas para volume (L), DQO ( $\left.\mathrm{mg} \mathrm{L}^{-1}\right), \mathrm{pH}$ e sólidos solúveis $\left({ }^{\circ} \mathrm{Bx}\right)$ da água gerada no processo de limpeza interna das máquinas

\begin{tabular}{c|c|c|c|c|c}
\hline $\begin{array}{c}\text { Linha de } \\
\text { produçáo }\end{array}$ & $\begin{array}{c}\text { No de } \\
\text { amostras }\end{array}$ & $\begin{array}{c}\text { Volume gerado/ } \\
\text { dia }(\mathbf{L})\end{array}$ & $\begin{array}{c}\text { DQO } \\
\left(\mathbf{m g ~ L}^{-1}\right)\end{array}$ & $\mathbf{p H}$ & $\begin{array}{c}\text { Sólidos solúveis } \\
(\mathbf{o} \mathbf{B x})\end{array}$ \\
\hline Linha 1 & 160 & 4.276 & 53.281 & 6,24 & 4,2 \\
\hline Linha 2 & 55 & 1.073 & 69.232 & 6,74 & 5,5 \\
\hline Linha 3 & 20 & 619 & 59.915 & 7,65 & 5,3 \\
\hline
\end{tabular}

A Linha 1 é a que tem o maior volume de água utilizado para limpeza interna das máquinas, portanto, foram coletadas mais amostras nesta linha. Esta possui um processo mais complexo e tem maior variedade de produtos, consequentemente necessita de limpezas com maior frequência. A Linha 2 abrange uma variedade menor de produtos e as limpezas ocorrem por número de bateladas, gerando menos limpezas diárias, porém a limpeza é feita em toda a tubulação, o que gera um volume elevado de água. A Linha 3 também faz limpezas por número de bateladas, no entanto, o processo é mais simples, pois somente é realizada a limpeza em parte da máquina na qual o alimento entra em contato, e por isso não exige um consumo tão grande de água.

Os resultados obtidos através da DQO, quando comparado entre as três linhas, indicam que há diferença estatística significativa entre a Linha 1 e 2 ( p < 0,05), mas não 
entre as Linhas 1 e $3(p>0,05)$ e nem entre as Linhas 2 e $3(p>0,05)$, conforme visualizado no Gráfico 1.

Gráfico 1- Média de DQO $\left(\mathrm{mg} \mathrm{L}^{-1}\right)$, desvio padrão e diferença entre as linhas de produção 1,2 e 3

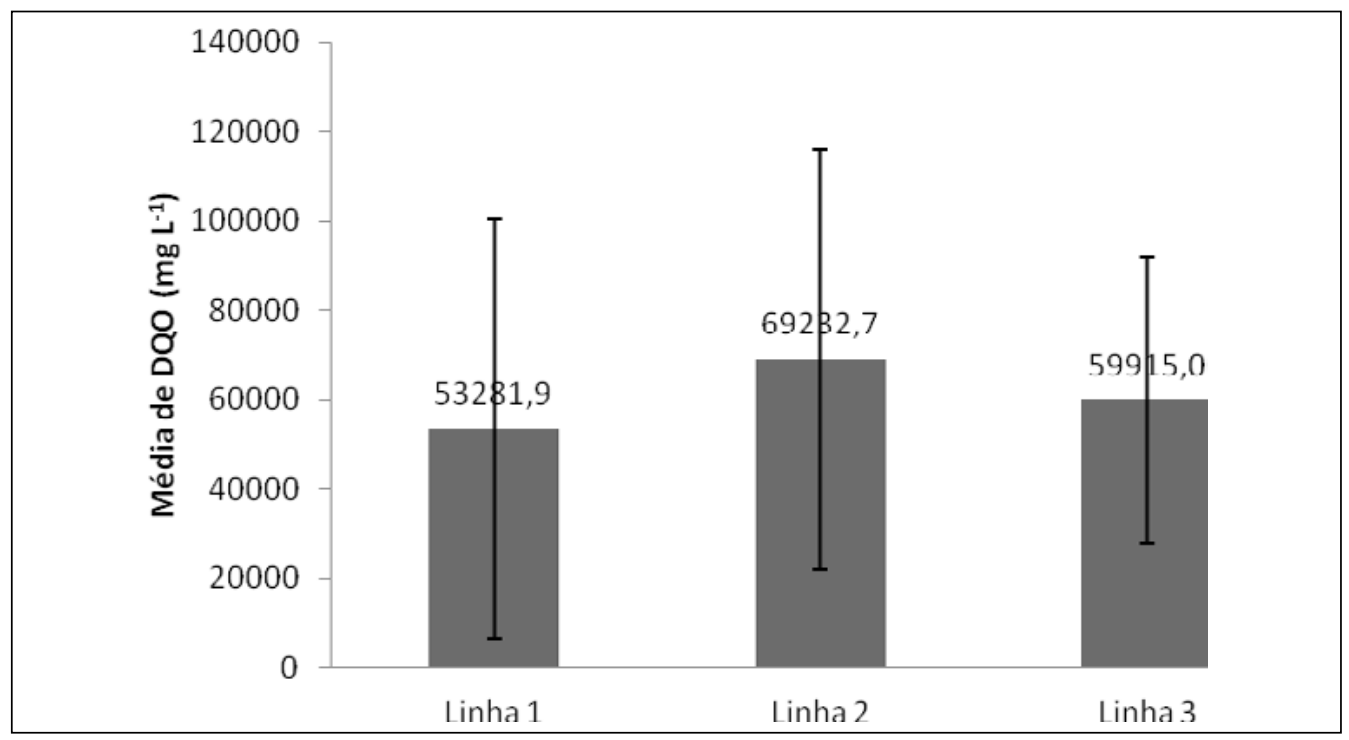

Considerando que as três linhas de produçáo produzem candies que possuem formulaçóes e matérias-primas diferentes, por isso é previsível que ocorra diferença nos resultados de DQO. A Linha 1 tem grande concentração de amido, açúcar e gelatina, a Linha 2, de açúcar e gelatina, e a Linha 3, de açúcar. Outro fator que pode interferir no valor da DQO é a quantidade de água utilizada nas limpezas de cada linha, ou seja, quanto mais água, mais diluida estará a carga orgânica.

Segundo Von Sperling (2005), a DQO indica a quantidade de oxigênio que um efluente consumiria em um corpo hídrico após seu lançamento e valores elevados podem indicar um alto potencial poluidor. Neste estudo, as três linhas apresentam um parâmetro de $\mathrm{DQO}$ com valores muito altos, devido à quantidade de matéria-prima que acaba sendo incorporada na água durante as limpezas. Para Tavares et al. (1998) a água com valores de DQO em torno de $9.000 \mathrm{mg} \mathrm{L}^{-1}$ não pode ser descartada direto no ambiente. Essa carga elevada de matéria orgânica interfere na eficiência do tratamento biológico, juntamente com o excesso de volume de água gerado pelas linhas de produçáo, além dos altos custos com produtos químicos como o hidróxido de sódio $(\mathrm{NaOH})$ que é utilizado para neutralização do efluente.

$\mathrm{Na}$ Linha 1 o pH foi de 6,24, na Linha 2, 6,74 e na Linha 3, de 7,65 indicando que não houve variação estatística significativa $\left(\chi^{2}=0,149 ; \mathrm{p}=0,93\right)$. 
Os resultados obtidos para sólidos solúveis $(\mathrm{B} \mathrm{Bx})$, cuja função é determinar o teor de açúcar dissolvido na água, indicam que não há diferença estatística significativa entre as três linhas ( $\mathrm{p}>0,05)$ conforme visualizado no Gráfico 2 .

Gráfico 2- Média de sólidos solúveis $\left({ }^{\circ} \mathrm{Bx}\right)$, desvio padrão e diferença entre as Linhas 1, 2 e 3

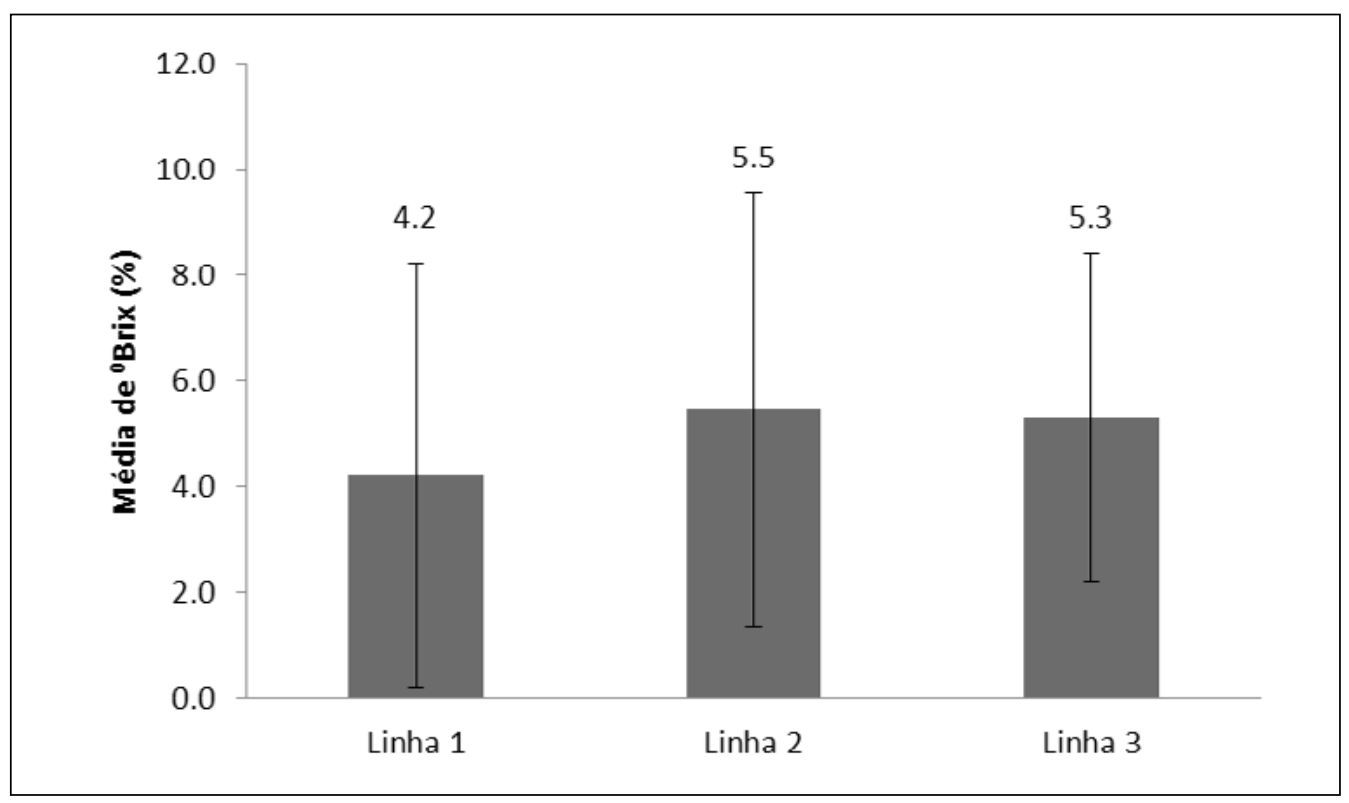

Esse resultado pode ocorrer, pois todos os ingredientes utilizados durante o processo produtivo (açúcar, amido e gelatina) são facilmente dissolvidos em água. As três linhas de produção geraram 5.968 litros de efluente por dia, com uma DQO média de $60.809 \mathrm{mg}$ $\mathrm{L}^{-1}$ e sólidos solúveis médio de $5,0^{\circ} \mathrm{Bx}$.

Com o intuito de garantir a segurança do alimento e em busca da caracterização desta água, as análises microbiológicas se tornam necessárias, pois todos os alimentos apresentam uma microbiota natural, no entanto, estão sujeitos a contaminações de bactérias, bolores e leveduras, através da manipulação inadequada, falta de higiene nos equipamentos e utensílios, podendo representar um risco a saúde (FRANCO; LANDGRAF, 2008).

Para a realização dos ensaios microbiológicos, foram levados em consideração os tipos de microrganismos que apresentam maior relação com o processo industrial, seja pelo tipo de matéria- prima utilizada, quanto pelo processo de manipulação e limpeza de equipamentos.

Os resultados da avaliação microbiológica da água de limpeza interna são apresentados na Tabela 2 . 
Tabela 2. Resultados das análises microbiológicas das Linhas 1, 2 e 3 da água de limpeza interna das máquinas

\begin{tabular}{c|c|c|c|c|c|c|c}
\hline & $\begin{array}{c}\text { Período } \\
\text { de coleta }\end{array}$ & CTBMA & BL & B. cereus & E.coli & S. aureus & Salmonella \\
\hline \multirow{2}{*}{ Linha 1 } & $\mathbf{0 0 h 0 0}$ & $<1,0 \times 10^{0}$ & $2,1 \times 10^{3}$ & $<1,0 \times 10^{0}$ & $<0,3$ & $<1,0 \times 10^{0}$ & Ausência \\
\cline { 2 - 7 } & $\mathbf{2 4 h 0 0}$ & $2,7 \times 10^{5}$ & $6,2 \times 10^{5}$ & $<1,0 \times 10^{0}$ & $<0,3$ & $<1,0 \times 10^{0}$ & Ausência \\
\hline \multirow{2}{*}{ Linha 2 } & $\mathbf{0 0 h 0 0}$ & $<1,0 \times 10^{0}$ & $3,0 \times 10^{1}$ est & $<1,0 \times 10^{0}$ & $<0,3$ & $<1,0 \times 10^{0}$ & Ausência \\
\cline { 2 - 8 } & $\mathbf{2 4 h 0 0}$ & $7,3 \times 10^{4}$ & $2,2 \times 10^{5}$ & $<1,0 \times 10^{0}$ & $<0,3$ & $<1,0 \times 10^{0}$ & Ausência \\
\hline \multirow{2}{*}{ Linha 3 } & $\mathbf{0 0 h 0 0}$ & $<1,0 \times 10^{0}$ & $8,3 \times 10^{3}$ & $<1,0 \times 10^{0}$ & $<0,3$ & $<1,0 \times 10^{0}$ & Ausência \\
\cline { 2 - 8 } & $\mathbf{2 4 h 0 0}$ & $1,7 \times 10^{5}$ & $2,2 \times 10^{6}$ & $<1,0 \times 10^{0}$ & $<0,3$ & $<1,0 \times 10^{0}$ & Ausência \\
\hline
\end{tabular}

00h00 - Primeira análise: Realizada no dia da coleta da amostra de água.

$24 \mathrm{~h} 00$ - Segunda análise: Realizada após 24 horas da coleta da amostra de água.

*CTBMA: Contagem total de bactérias mesófilas aeróbias.

**BL: Bolores e leveduras.

Resultados para CTBMA, Bolores e leveduras, Bacillus cereus e Staphylococcus aureus expressos em UFC mL ${ }^{-1}$, para Escherichia coli, NMP mL ${ }^{-1}$ e Salmonella spp. em $25 \mathrm{~mL}$ de água analisada.

est.: estimado.

Conforme apresentado na Tabela 2, percebe-se que não houve presença de Bacillus cereus, Escherichia coli, Salmonella spp. e Staphylococcus coagulase positiva, nas Linhas 1, 2 e 3 tanto na primeira análise, quanto na segunda. Acredita-se que esse resultado seja decorrente de limpezas bem realizadas, conforme os procedimentos exigidos pela empresa (boas práticas de fabricação), higienização adequada dos equipamentos, assim como dos colaboradores e procedência confiável da matéria-prima.

Para CTBMA não houve crescimento na primeira análise (00h00), mas para a análise realizada 24 h após a coleta, houve crescimento de 5 logs (reprodução extremamente ativa das bactérias) na Linha 1 e na Linha 3 e 4 logs na Linha 2. Essa contaminação pode ser decorrente de algum procedimento de limpeza inadequado, higienização ou contaminação da matéria-prima, juntamente ao tempo excessivo de armazenamento da água. As bactérias crescem rapidamente em condições ideais, podendo ser encontradas em qualquer ambiente. Esse tipo de análise (CTBMA) acaba detectando uma gama de bactérias que se desenvolvem em ambientes aeróbios e que apresentam temperaturas ótimas em torno de 37 ${ }^{\circ} \mathrm{C}$. Para BL, houve uma contaminação inicial $(00 \mathrm{~h} 00)$ e crescimento após $24 \mathrm{~h}$. A Linha 1 apresentou 2 logs de crescimento, a Linha 2 apresentou 4 logs e a Linha 3 apresentou 3 logs. Os fungos toleram ambientes secos com altas concentraçôes de açúcar, no entanto, seu desenvolvimento é mais lento. A metodologia utilizada detecta fungos filamentosos (bolores e mofos) e leveduras, pois os BL estão em todos os ambientes e são nutricionalmente versáteis. Atualmente não existem parâmetros microbiológicos aplicáveis para água de reúso em indústrias de alimentos, portanto não existe a possibilidade de haver comparaçóes.

A determinação do tempo de crescimento microbiológico para as análises de contagem total de bactérias mesófilas aeróbias (CTBMA) e bolores e leveduras (BL) é fundamental para indicar o período que esta água de reúso poderá ser armazenada, e os resultados desta análise estão apresentados no Gráfico 3. 
Gráfico 3- Período médio de crescimento microbiológico para a primeira (00h00) e para a segunda análise (24h00) de contagem total de bactérias mesófilas aeróbias (CTBMA) e bolores e leveduras (BL) em unidades formadoras de colônias (UFC $\mathrm{mL}^{-1}$ ) das três linhas analisadas

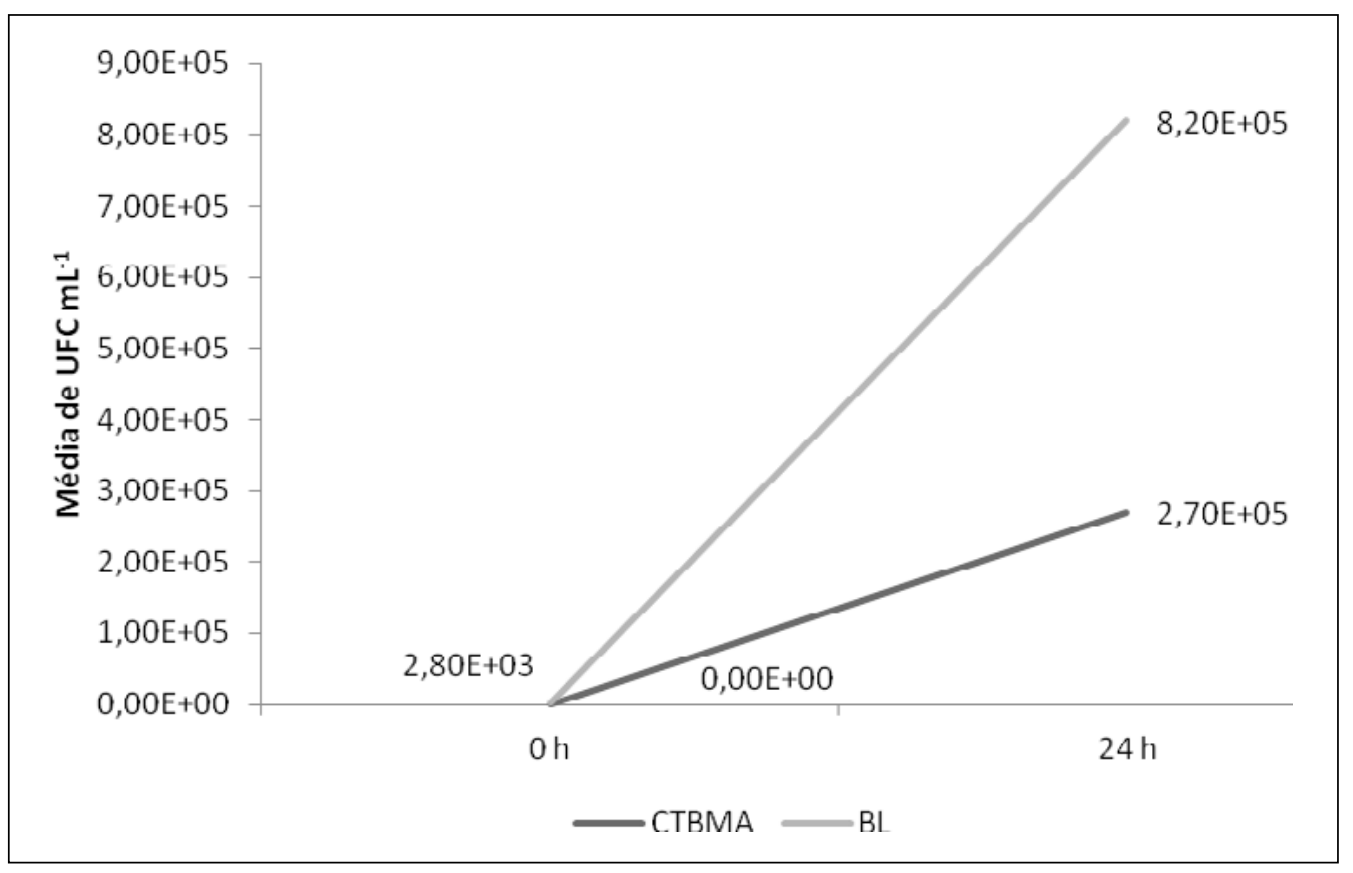

Os resultados apresentados no Gráfico 3 demonstram que havia uma contaminação inicial pequena para $\mathrm{BL}$, no entanto, essa contaminação cresceu quando a água foi armazenada por um período maior de 24 h após sua geração, apresentando também contaminaçáo para CTBMA.

Os controles para a microbiologia de alimentos podem ser realizados através da remoção por filtros, manutençẫo das condições atmosféricas, altas temperaturas, baixas temperaturas, desidratação, conservantes químicos, irradiação, destruição mecânica dos microrganismos com altas pressóes (FRANCO; LANDGRAF, 2008). Algumas alternativas que a empresa poderá utilizar são filtros com carvão e terra diatomácea, sistema de osmose reversa ou ainda fotólise por radiação ultravioleta.

Não foram encontrados trabalhos que utilizem a água de reúso para ser incorporada na produção de alimentos. Em geral, a água de reúso tem outros fins, como resfriamento de máquinas ou caldeiras. Resultados semelhantes ao deste trabalho foram encontrados no trabalho de Luersen et al. (2012) quando pesquisaram a possibilidade de reutilizar o efluente tratado no processo produtivo da Indústria Curtidora. O reúso náo alterou a aparência dos artigos de couro.

A água de reúso também traz benefícios para a agricultura. Os efluentes provenientes de sistemas de lodo ativado tem maior concentraçáo de nutrientes, reduzindo ou eliminando 
o uso de fertilizantes e aumentando a produtividade agrícola. A irrigação com esgotos promove a concentração de matéria orgânica, aumentando a capacidade de retenção de água do solo (HESPANHOL, 2002). Dantas et al. (2014) averiguaram a viabilidade do uso de água residuária tratada na irrigação da cultura do rabanete (Raphanus sativus L.) através da irrigação de efluentes com diferentes concentraçóes, concluindo a viabilidade do efluente para a irrigação independente da diluição utilizada no tratamento.

Por meio dos resultados obtidos na caracterização físico-química e microbiológica pode-se inferir que esta água é viável para reúso em um período inferior a $24 \mathrm{~h}$ após seu primeiro uso. Deve-se considerar que o reúso referido no presente trabalho refere-se ao emprego da água na lavagem de maquinários, pisos, banheiros e na rega de jardins.

Contudo, é importante salientar que é necessária a avaliação de como inseri-la adequadamente no processo, para não comprometer a qualidade do produto final, pois, como disse Dantas e Sales (2009), para colocar em prática o reúso, é preciso investir em um sistema de tratamento de água de acordo com as características do efluente, finalidade da aplicação e a viabilidade econômica da implantação deste sistema.

A água gerada na limpeza dos processos produtivos, para seu reúso, deverá passar por um sistema de filtração e cozimento a fim de remover impurezas, cor e microrganismos presentes. Algumas das opçóes descritas na literatura para melhorar a qualidade da água utilizada em indústrias são filtros com carvão e terra diatomácea ou ainda fotólise por radiação ultravioleta (GOULART et al., 2011; SUBTIL; MIERZWA; HESPANHOL, 2009). Também descrito como um sistema biológico com resultados satisfatórios no tratamento de efluentes com foco em reúso é o Contador Biológico Rotativo (CBR), cujo processo fornece condiçôes para crescimento de microrganismos em um biofilme estático, o que permite a aplicação de maiores cargas orgânicas e uma maior resistência a choques tóxicos, segundo Subtil et al. (2016).

\section{CONCLUSÃO}

No processo de limpeza interna das máquinas da indústria de candies alvo deste estudo são utilizados aproximadamente 6.000 L de água por dia. Esta água possui elevada DQO e graus Brix, ausência de B. cereus, E. coli, S. aureus e Salmonella spp., baixa contaminação de bolores e leveduras e também de contagem total bactérias mesófilas aeróbias, durante as primeiras $24 \mathrm{~h}$. Após este período, constatou-se aumento em todas as contagens microbiológicas. Isto demonstra que o reúso da água de forma não potável, deve ser feito dentro de 24 h após o primeiro uso.

\section{REFERÊNCIAS}

ARAÚJO, B. M.; SANTOS, A. S. P.; SOUZA, F. P. Comparativo econômico entre o custo estimado do reúso do efluente de ETE para fins industriais não potáveis e o valor da água potável para a região sudeste do Brasil. Perspectivas on line, Rio de Janeiro, v. 7, n. 17, p. 51-61, 2017. 
BDR - Banco de Dados Regional. Perfil socioeconômico do Vale do Taquari. Lajeado: Univates, 2011.

BRASIL. Conselho Nacional de Recursos Hídricos - CNRH. Resolução No 54, de 28 de novembro de 2005 - Estabelece critérios gerais para reúso de água potável. Estabelece modalidades, diretrizes e critérios gerais para a prática de reúso direito não potável de água, e dá outras providências.

BRASIL. Ministério da Agricultura, Pecuária e Abastecimento. Portaria no76 de 26 de novembro de 1986. Dispóe sobre os métodos analíticos de bebidas e vinagre. Diário Oficial da República Federativa do Brasil, Brasília, 28 nov. 1986. Seção 1, pt. 2.

BRASIL. Ministério da Agricultura, Pecuária e Abastecimento. Secretaria de defesa agropecuária. Instrução normativa no 2 , de 26 de agosto de 2003 . Oficializar os métodos analíticos oficiais para análises microbiológicas para controle de produtos de origem animal e água. Diário Oficial da República Federativa do Brasil, Brasília, 18 set. 2003. Seção 1, P.14.

CUNHA, A. H. N. et al. O reúso de água no Brasil: A importância da reutilização de água no país. Enciclopédia Biosfera, Centro Científico Conhecer, GO, Brasil, v. 13, p. $1225,2011$.

DANTAS, D. L.; SALES, A.W. C. Aspectos ambientais, sociais e jurídicos do reúso da água. Revista de Gestáo Social e Ambiental, São Paulo, v. 3, n. 3, p. 4-19, 2009.

DANTAS, I. L. de A. et al. Viabilidade do uso de água residuária tratada na irrigação da cultura do rabanete (Raphanus sativus L.). Revista Ambiente e Água, Taubaté, v. 9, n. 1, 2014.

ECKHARD, C. L. Aplicaçáo do método de produçáo mais limpa: estudo de caso em uma indústria de candies. 2014. 110f. Dissertação (Mestrado em Ambiente e Desenvolvimento) - Centro Universitário UNIVATES, Lajeado, 2013.

FRANCO, B. D, G. de M.; LANDGRAF, M. Microbiologia dos Alimentos. São Paulo: Atheneu. 2008. 182 p.

GOULART, M. R. et al. Metodologias para reutilização do resíduo de terra diatomácea, proveniente da filtração e clarificação da cerveja. Química Nova, São Paulo, v. 34, n. 4, p. 625-629, 2011.

HESPANHOL, Ivanildo. Potencial de Reúso de Água no Brasil Agricultura, Indústria, Municípios, Recarga de Aquíferos. Revista Brasileira de Recursos Hídricos, Porto Alegre, v. 7, n. 4, p. 75-95, 2002. 
IBGE. Instituto Brasileiro de Geografia e Estatística. Cidades@. Rio de Janeiro: IBGE, 2015.

IBGE. Instituto Brasileiro de Geografia e Estatística. Demografia das empresas 2010. Rio de Janeiro: IBGE, 2012.

ISO 7932:2004. Microbiology of food and animal feeding stuffs - Horizontal method for the enumeration of presumptive of Bacillus cereus - colony-count technique at $30^{\circ} \mathrm{C}$.

LUERSEN, K.H. et al. Reúso do efluente tratado na indústria curtidora. Tecno-Lógica, Santa Cruz do Sul, v. 16, n. 1, p. 05-10, 2012.

MIERZWA, J. C., HESPANHOL, I. Água na indústria: uso racional e reúso. Otimização do uso e reúso da água: necessidades e desafios. São Paulo: Oficina de Textos. 2005. p. 20.

MORAES, D. S. de L.; JORDÃO, B. Q. Degradação de recursos hídricos e seus efeitos sobre a saúde humana. Revista de Saúde Pública, São Paulo, v. 36, n.3, p. 370-374, 2002.

PARRON, L. M., MUNIZ, D. H. de F., PEREIRA, C. M. Manual de procedimentos de amostragem e análise físico-química de água. Dados eletrônicos - Colombo: Embrapa Florestas/PR, 2011. Disponível em: <http://www.cnpt.embrapa.br/publica/ seriedoc/edicoes/doc219.pdf> Acesso em 09 de outubro de 2015.

SUBTIL, E. L. et al. Potencial de reúso de água na lavagem de caminhóes utilizando Contador Biológico Rotativo. Revista Ambiente e Água, Taubaté, v.11, n. 4, p. 851-866, 2016.

SUBTIL, E. L.; MIERZWA, J. C.; HESPANHOL, I. Avaliação do desempenho do sistema $\mathrm{UV} / \mathrm{H}_{2} \mathrm{O}_{2}$ no tratamento de efluentes provenientes do processo de tratamento térmico de emulsôes de água e óleo. Revista Ambiente e Água, Taubaté, v. 4, n. 3, p. 169-180, 2009.

TAVARES, V. B. et al. Utilização do resíduo líquido de indústria de processamento de suco de laranja como meio de cultura de Penicillium citrinum: depuração biológica do resíduo e produção de enzima. Química Nova, São Paulo, v. 21, n. 6, p. 722-725, 1998.

TELLES, D. D.; COSTA, R. H. P. G. Reúso da água: conceitos, teorias e práticas. "Consumo de água”, "Reúso". 1 ed. São Paulo: Blucher, 2007.

VON SPERLING, M. Introdução à Qualidade das Águas e Tratamento de Esgotos. 3. ed. Belo Horizonte: Departamento de Engenharia Sanitária e Ambiental; Universidade Federal de Minas Gerais; 2005. 